Moreira, J.F.R.; Almeida, M.G. O lugar Kalunga como lugar turístico: um olhar sobre o turismo rural no Engenho II em Cavalcante (GO). Revista Brasileira de Ecoturismo, São Paulo, v.6, n.3, ago/out-2013, pp.708-721.

\title{
O lugar Kalunga como lugar turístico: um olhar sobre o turismo rural no Engenho II em Cavalcante (GO)
}

\author{
The Kalunga's place of the tourist place: a glimpse into rural tourism \\ in Engenho II (Cavalcante, GO, Brazil)
}

\section{Jorgeanny de Fátima Rodrigues Moreira, Maria Geralda de Almeida}

\section{RESUMO}

No presente artigo apresentamos algumas reflexões e discussões acerca do desenvolvimento do turismo cultural e rural no Engenho II. Essa comunidade é constituída por remanescentes de quilombolas e localiza-se no município de Cavalcante, nordeste de Goiás. A atividade turística nessa comunidade é uma prática bastante incipiente, mas tem-se configurado como uma alternativa para o complemento de renda e amenização do êxodo rural. Os principais potenciais dessa área são os atrativos naturais e as práticas culturais, em especial suas manifestações festivas. No entanto, cabe investigar se a apropriação do turismo contribui para a preservação desses valores ou representa apenas mais um envolvimento efêmero e fugaz entre turista e lugar turístico. Pesquisas bibliográficas sobre o tema, observação e entrevistas com moradores são aportes teóricos e metodológicos que subsidiam o desenvolvimento da discussão. As possibilidades para o desenvolvimento do turismo na área são grandes, mas os Kalunga enfrentam desafios para a efetivação dessa atividade, conforme foram detalhados nas considerações finais.

PALAVRAS-CHAVE: Kalunga; Quilombolas; Comunidade Local; Turismo Rural.

\section{ABSTRACT}

In this article we presents some discussions about the development of cultural and rural tourism in the Engenho II. This community are remnants of quilombola. Is the located in the Cavalcante, Goias northern, Brazil. The activities of tourism in this community are practices fairly crude, but it has been configured as an alternative to income supplement and mitigate the rural exodus. The main potential of this area are the natural attractions, but as regards cultural practices. However it is worth investigating whether the ownership of tourism contributes to the preservation of those values or involvement is just another ephemeral and fleeting between tourist and tourist place. Research literature on the subject, observation and interviews with residents are theoretical and methodological contributions that support the development of the discussion. The possibilities for the development of tourism in the area is great, but as we'll see, Kalunga face challenges in the realization of this activity, as investments for the implementation of tourism infrastructure, involvement of the entire population and degradation of the attractions.

KEY-WORDS: Kalunga; Quilombolas; Local Community; Rural Tourism. 


\section{Introdução}

A busca pela prática do turismo em comunidades rurais tem se tornado cada vez mais frequente. Essa procura se dá pela valorização do meio natural e bucólico. As paisagens simbólicas presentes no meio rural promovem a idealização dos indivíduos que procuram descanso e contato com a natureza.

A paisagem cultural dessas áreas também intensifica a procura, pois remete ao turista, o olhar sobre as atividades praticadas no campo, como a fabricação de alimentos com frutos e legumes colhidos nas roças e as celebrações religiosas que acontecem no meio rural.

Em decorrência, alguns municípios brasileiros têm se adaptado a atividade turística, ao implantar novos empreendimentos. O atendimento à demanda turística é uma alternativa para as comunidades que vivem da agricultura familiar, já que a modernização no campo e a expansão dos grandes produtores agrícolas impossibilitam a competição do pequeno agricultor no mercado agropecuário.

O turismo é uma oportunidade para a geração de emprego e renda, além de promover a qualidade de vida da população local. No meio rural, essa atividade pode tornar-se uma estratégia para o desenvolvimento, ao explorar economicamente os aspectos culturais e simbólicos.

As potencialidades turísticas podem ser apropriadas, com base comunitária fortalecida pelo associativismo e/ou cooperativismo. Dessa forma, toda a comunidade é beneficiada, por meio da geração de emprego, inclusão social e desenvolvimento, que ocorre na medida em que a população local participe nas tomadas de decisões.

No presente artigo pretendemos discutir o desenvolvimento da atividade turística em uma comunidade rural habitada por descendentes de quilombolas, identificados como Kalunga: o Engenho II. Essa comunidade localiza-se em Cavalcante, Goiás a aproximadamente $400 \mathrm{~km}$ de Brasília. Nela, seus potenciais turísticos como cachoeiras, trilhas e paisagens culturais são explorados principalmente por empreendimentos situados no centro urbano de Cavalcante, como agências de viagens e guias turísticos.

A apropriação do turismo por parte da própria comunidade do Engenho II, ainda é bastante incipiente, tendo como principais atividades: a condução de turistas pela área; casas em que seus moradores vendem almoços, lanches, bebidas e artesanatos; aluguel dos quintais para camping.

Pretende-se com o texto responder as seguintes indagações: Como acontece o envolvimento da população local para o desenvolvimento da atividade turística no Engenho II? Quais cooperações e conflitos que emergem com este envolvimento? O turismo na área rural dos quilombolas permite a valorização e preservação do patrimônio natural e cultural da comunidade? O lugar Kalunga, pautado nos laços simbólicos de pertencimento, se configura em mais um lugar turístico, caracterizado pela relação fugaz e efêmera próprias dessa atividade?

Esse artigo foi dividido em três partes teóricas contendo algumas reflexões acerca do turismo de base comunitária e a análise do desenvolvimento da atividade 
turística no Engenho II. Nessa discussão, apresentaremos alguns dados coletados em campo, com base na observação e entrevistas com alguns moradores no período compreendido entre os meses de julho de 2011 a janeiro de 2012.

\title{
Apontamentos para se pensar o turismo cultural e de base comunitária em áreas rurais
}

A prática do turismo em comunidades rurais é considerada uma estratégia para o desenvolvimento local e o resgate da autoestima do homem do campo, na medida em que ocorre a valorização da identidade cultural incentivada pela presença de moradores do centro urbano. $O$ turismo rural também contribui para estimular a produção, o empreendedorismo e a manutenção das famílias no campo, ao diminuir o fluxo migratório campo-cidade. Além disso, o turismo auxilia na persistência sociocultural das formas tradicionais de produção.

O conceito de Turismo adotado pelo Ministério do Turismo, "fundamenta-se em aspectos que se referem ao território, à base econômica, aos recursos naturais e culturais e à sociedade" (BRASIL, 2009, p.313). O Turismo Rural é conceituado pelo mesmo órgão como "um conjunto de atividades turísticas desenvolvidas no meio rural, comprometidas com a produção agropecuária, agregando valor a produtos e serviços, resgatando e promovendo o patrimônio cultural e natural da comunidade" (BRASIL, 2009, p.19).

Esse tipo de turismo é considerado uma atividade capaz de agregar valor as práticas rurais e gerar renda a população, permitindo que as atividades ligadas a agricultura e pecuária continuem sendo executadas. Moletta (2002) classifica o turismo rural como

\begin{abstract}
uma atividade de lazer que o homem urbano procura junto às propriedades rurais produtivas, buscando resgatar suas origens culturais, 0 contato com a natureza e a valorização da cultura local. Já para o homem do campo, significa um meio para aumentar a sua renda mensal, de forma harmônica, valorizando sua propriedade e o seu estilo de vida (MOLETTA, 2002, p. 9).
\end{abstract}

Nessa perspectiva, o turismo rural, assim como os demais segmentos turísticos, tem o objetivo de proporcionar lazer aos moradores de centros urbanos e gerar renda para o destino turístico. Enquanto que para o homem do campo, a prática do turismo permite a valorização dos símbolos e costumes da vida no meio rural. Campanhola e Silva defendem que essa segmentação:

Ao mesmo tempo em que depende da gestão do espaço local e rural para o seu sucesso, contribui para a proteção do meio ambiente e para a conservação do patrimônio natural, histórico e cultural do meio rural. Representa, portanto, um instrumento de estímulo à gestão e ao uso sustentável do espaço local, que devem beneficiar prioritariamente a população local direta e indiretamente envolvida com as atividades turísticas (CAMPANHOLA; SILVA, 2000, p.152). 
Os autores defendem o turismo rural como propulsor da valorização dos aspectos culturais e tradicionais no campo, ao mesmo tempo em que beneficia o pequeno proprietário ao gerar renda e o uso equilibrado do espaço local. Além disso, a população é a principal gestora dessa atividade e quem define o perfil do turista que deseja na propriedade. Em decorrência, contribui para o melhor uso do espaço rural, evitando a degradação dos atrativos utilizados.

A importância em se criar alternativas para a complementação da renda no meio rural, deve-se as transformações nas relações de produção no campo, que tem dificultado a relação do campesino ao modo de vida tradicional. A modernização na agricultura, como o emprego de técnicas mais sofisticadas e instrumentos que precisam ser adquiridos a preços mais elevados, inviabiliza as técnicas empregadas nas pequenas propriedades rurais baseadas na agricultura familiar, uma vez que a "produção familiar se caracteriza pelo trabalho familiar na exploração agropecuária e pela propriedade dos meios de produção" (MARAFON; RIBEIRO, 2006, p. 112).

A concentração de renda na região Sul de Goiás, em virtude de processos de ocupação, povoamento, modernização e mecanização no campo de forma mais intensa, conferiu as regiões norte e nordeste de Goiás, um processo lento na dinâmica econômica. Isso se deve aos "grandes problemas próprios de nossa formação periférica e das ações direcionadas para o crescimento de determinadas regiões do estado" (ARRAIS, 2004, p.59).

Para o autor, a pobreza da região norte/nordeste é consequência da "ação dos grupos econômicos aliados ao Estado, que reforçaram a acumulação do capital" nas regiões Sul e Sudeste goiano. Em decorrência, fenômenos como o êxodo rural, principalmente dos mais jovens em busca de melhores condições de vida, são comuns nas demais regiões de Goiás.

O turismo pode ser uma alternativa para abrandar essas desigualdades, contribuindo para a complementação da renda familiar, (re) significando os valores e costumes das comunidades e fortalecendo os laços desses indivíduos com o lugar.

No entanto, não há políticas públicas ligadas ao interesse de desenvolvimento do turismo no meio rural, no norte e nordeste do estado de Goiás. A comunidade Engenho II em Cavalcante, Goiás (Figura 1) é liderada por um morador que representa a comunidade junto ao município, ao estado e ao mercado privado. Esse representante organiza e mobiliza os moradores, que mostram interesse na atividade turística, no intuito de fortalecer o associativismo.

Sob a liderança desse representante - presidente e/ou líder local responsável por todas as atividades do lugar -, os Kalunga do Engenho II desenvolvem, de maneira bastante incipiente, o turismo de base comunitária. A comunidade, a partir de uma decisão interna, trabalha junto à associação. Nas palavras de Irving:

[...] o turismo de base comunitária resulta de uma demanda direta dos grupos sociais que residem no lugar turístico, e que mantém com este território uma relação cotidiana de dependência e sobrevivência material e simbólica. Assim, não é possível imaginar uma iniciativa de turismo de base comunitária resultante de uma decisão externa, de uma intervenção exógena à realidade e aos modos de vida locais (IRVING, 2009, p.112). 

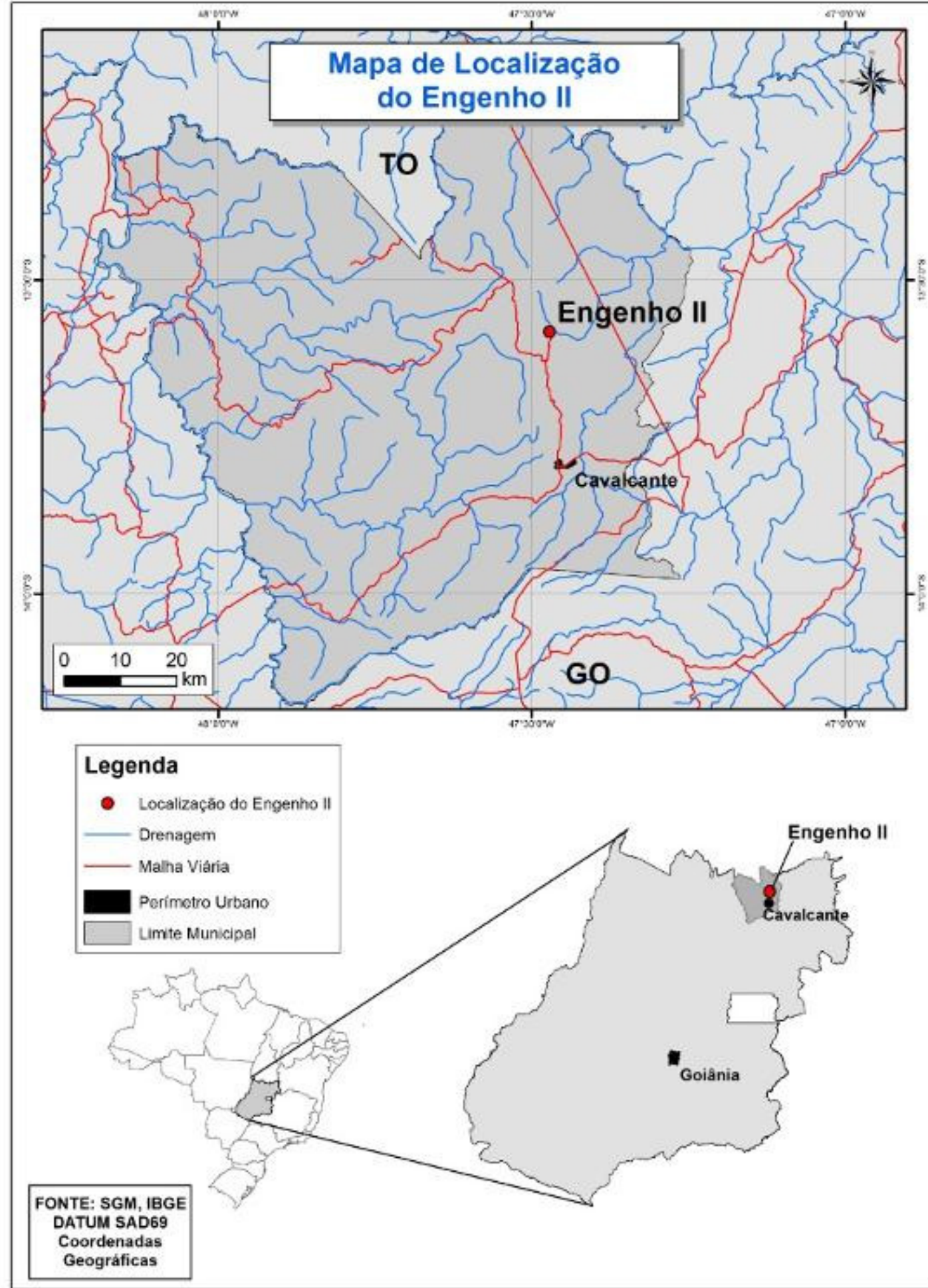

Figura 1: Mapa de Localização. Organização: Jorgeanny de Fátima R. Moreira; Elaboração: Alexandre Henrique Cardoso. Setembro de 2012.

Figure 1: Location Map. Organization: Jorgeanny Fatima R. Moreira; Prepared by: Alexandre Cardoso. September 2012. 
No Engenho II, as iniciativas dos trabalhos ligados ao turismo partem dos próprios moradores. Esses indivíduos conhecem as necessidades da comunidade, bem como suas potencialidades, e por meio do associativismo organizam e implantam as atividades que podem ser desenvolvidas pela população local.

O associativismo tem como base o trabalho em cooperação e a participação de um grupo social com interesses em comum. Por meio da organização social, visando à melhoria da qualidade de vida e o desenvolvimento local, a comunidade trabalha no sentido de desenvolver estratégias para a produção solidária.

Essa alternativa pode promover a inclusão social, por meio do processo de desenvolvimento da atividade turística. Além de fortalecer as relações entre os moradores, esse tipo de turismo valoriza a cultura local, na medida em que incentiva a relação de pertencimento ao lugar em que se vive.

A Associação dos Condutores de Turismo Kalunga no Engenho II, recebe jovens de 18 a 35 anos de idade, de ambos os sexos, interessados em trabalhar como condutores de turismo na área do quilombo. Essa associação constitui-se de um grupo de 70 pessoas sob a liderança do presidente e/ou líder local. Esse morador tem a responsabilidade de coordenar as atividades do grupo, organizando roteiros e escalas de guiamento para os envolvidos, de forma que todos tenham trabalho ao longo da semana.

As reuniões acontecem na casa desse líder, bem como as saídas com os turistas para o guiamento pelas trilhas e cachoeiras da comunidade. Cada guia cobra cinquenta reais para acompanhar um grupo com até seis turistas. Do valor cobrado, dez por cento é destinado à Associação, esse dinheiro é revertido em equipamentos e serviços para a comunidade.

Há famílias que não pretendem se dedicar ao mercado turístico. Alguns moradores não acreditam nessa atividade como uma forma de melhoria na qualidade de vida. Em muitos casos, apenas um membro da família é condutor. Esses trabalhadores são jovens que veem no turismo uma forma de não emigrar para os centros urbanos. Um dos guias Kalunga conta que residiu durante seis meses em Brasília, mas preferiu voltar ao Engenho II, pois não se adaptou a rotina da capital federal.

Com o associativismo, a comunidade é quem participa da tomada de decisões e pode influenciar o desenvolvimento comercial ao administrar os ganhos ligados ao turismo. Além disso, o trabalho em conjunto pode aumentar a tolerância dos moradores em relação ao turismo, já que este pode ocasionar a intensificação do uso do espaço por indivíduos que não são daquele lugar.

O envolvimento da comunidade no processo de desenvolvimento da prática turística, também pode reduzir os impactos negativos do turismo (SWARBROOKE, 2000). A degradação dos atrativos turísticos e a mudança na rotina dos moradores podem ser controladas, a partir da participação e conscientização de toda a comunidade local, no sentido de se pensar estratégias para promover o turismo de forma responsável e solidária. 
A fim de evitar conflitos entre moradores e turistas no uso do espaço, Irving (2009) propõe pensar o lugar como ponto focal da transformação social, ou seja, é necessário que o morador veja as singularidades e particularidades do seu lugar como o principal atrativo turístico, e em consequência, o fator essencial para o desenvolvimento da qualidade de vida da população local. Segundo a autora

o turismo, em qualquer de suas formas de expressão e intervenção, interfere na dinâmica socioambiental de qualquer destino, o turismo de base comunitária só poderá ser desenvolvido se os protagonistas deste destino forem sujeitos e não objetos do processo (IRVING, 2009, p.111).

Portanto, no turismo de base comunitária é a população quem toma as decisões, é ela quem decide o perfil do turista que deseja receber e o que deve ser explorado enquanto atrativo. A atividade turística pode contribuir para a intensificação dos laços sociais, entre os próprios moradores e destes com os turistas. Para a efetivação do turismo de base comunitária é necessário à motivação e o envolvimento da comunidade local no seu desenvolvimento.

\section{Potencialidades para o desenvolvimento do turismo rural no Engenho II}

O meio rural adquiriu o valor de lugar turístico por responder a uma demanda contínua de turistas interessados em suas cachoeiras, trilhas, serras e práticas culturais. Almeida (2007) explica que o desejo por conhecer novos lugares está no desejo de desterritorializar-se a partir da imagem criada pelo turismo. Nas palavras da autora

[...] a propaganda que the dá o corpo, faz com que o homem procure cada vez mais a fantasia, o exotismo, a nostalgia, o novo, o diferente, sendo a natureza o que mais se presta a atender os apelos do imaginário do homem citadino, por excelência, o turista (Almeida, 2007, p.102-103).

A busca do citadino por áreas "naturais" revela uma apropriação sobre o ambiente e se mostra como um mecanismo que transforma intensamente o espaço. $O$ turismo transforma os aspectos naturais e sociais de determinada sociedade em um produto para o mercado do lazer. O turismo rural é um exemplo da efetivação da relação, ente o natural e o cultural.

No Engenho II, a motivação pela busca do turismo se dá pela extensa área natural e pelas práticas culturais da população local. No espaço habitado pelos Kalunga predomina os vãos, serras e morros, depressões e vales estreitos, com a presença de rios e uma vegetação típica do cerrado "stricto sensu", pois "apresenta maior densidade de árvores em relação às formas arbustivas e herbáceas, [...] com altura média variando entre 3 e 8 metros" (OLIVEIRA, 2005, 184) (Figura 2). 


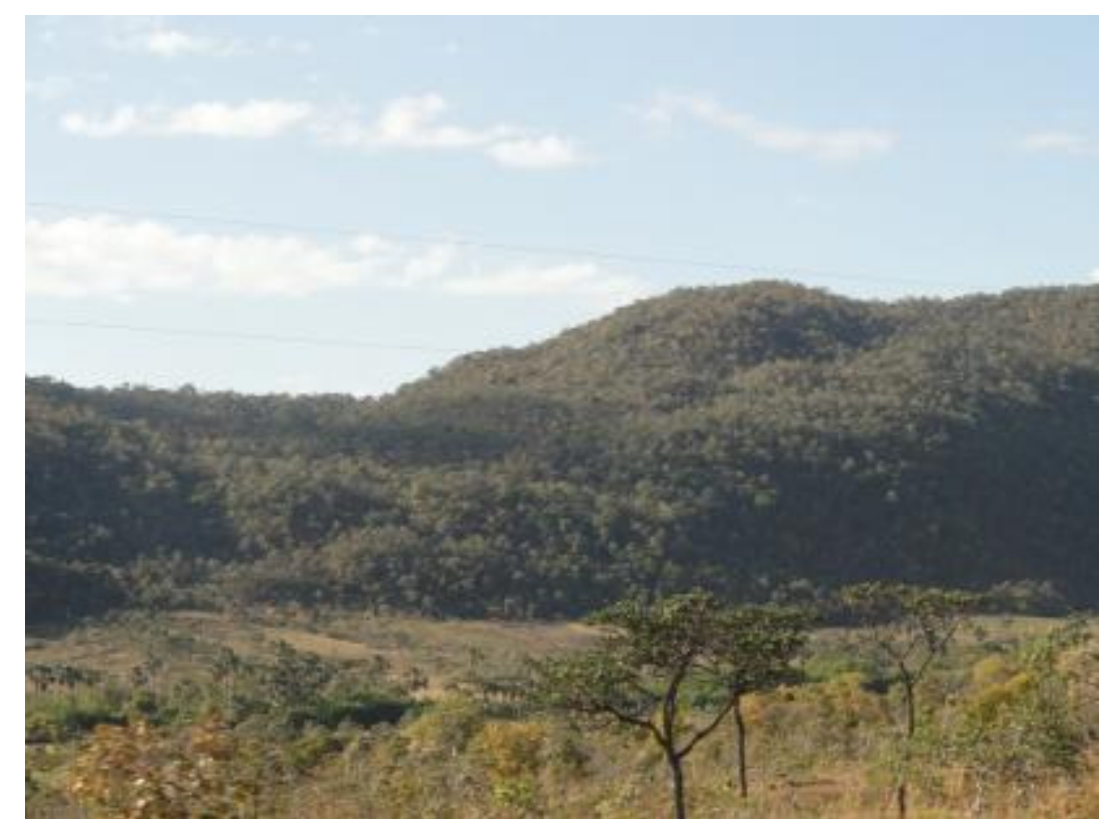

Figura 2: Vegetação Serra Geral, Cavalcante (GO) - Vista Engenho II. Foto: Jorgeanny de Fátima R. Moreira, Julho de 2011.

Figure 2: Vegetation Serra Geral, Cavalcante (GO) - View of Engenho II. Photo: Jorgeanny Fatima R. Moreira, July 2011.

Esse espaço é conhecido como "Vãos da Serra Geral, parte ocupado pelo vale do Rio Paranã e seus afluentes, às bordas da Chapada dos Veadeiros na qual se encontra o Parque Nacional da Chapada dos Veadeiros" (ALMEIDA, 2003, p. 3). Além dos aspectos naturais, as manifestações culturais e religiosas dos Kalunga evidenciam a construção da identidade com o lugar, a partir da (re) significação das tradições estabelecidas na organização do trabalho, política e sociedade.

Esses aspectos se configuram como um atrativo turístico para moradores de cidades como Cavalcante, Brasília e Goiânia. Tanto os atrativos culturais, quanto os naturais, como as cachoeiras Santa Bárbara e Capivara, localizadas no Engenho II, são os mais procurados na Serra Geral. Os turistas que buscam por esses lugares são tentados a participar das festas, uma vez que essas manifestações despertam a curiosidade dos visitantes, deslumbrados com o mito de que essa sociedade vivia sob o isolamento até meados da década de 1970.

Alguns turistas, presentes no mês de julho de 2012, afirmavam estar ansiosos para conhecer a comunidade, esperando encontrar um grupo social com os mesmos hábitos, costumes e alimentos do período colonial. Sr. S. B. M. (Advogado, morador de Brasília) argumenta que esperava ver algumas danças de origem africana com traços do Candomblé ou Umbanda. Estava surpreso em encontrar "uma comunidade rural de fé católica". O advogado e sua família ficaram fascinados com o modo de vida simples do campo e com os alimentos orgânicos vendidos em algumas casas Kalunga (Figura 3). 


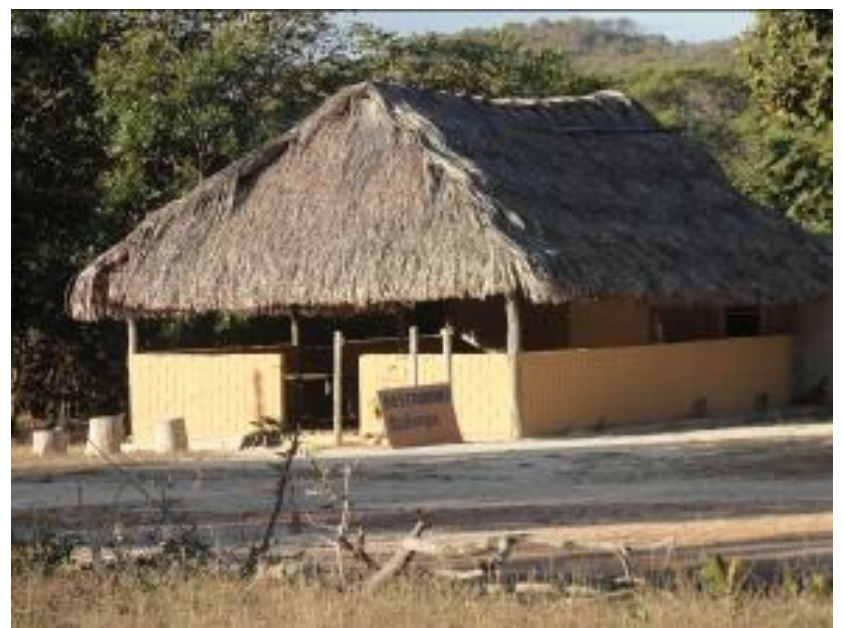

Figura 3: Restaurante Kalunga - Engenho II. Foto: Jorgeanny de Fátima R. Moreira, Julho de 2011.

Figure 3: Restaurant Kaluga - Engenho II. Photo: Jorgeanny Fatima R. Moreira, July 2011.

A relação com o espaço de vivência e cotidiano dos moradores pode ser apreendido pelos turistas, quando acompanhados pelos condutores de turismo Kalunga e moradores do Engenho II. Nesses roteiros os condutores locais apresentam a área quilombola e falam sobre o modo de vida e as lendas que envolvem o surgimento do quilombo.

Alguns turistas participam das festas de encerramento das folias de Santos Reis e de Santo Antônio, nos meses de Janeiro e Julho respectivamente. É nesse momento que acontece, de forma mais intensa o contato entre visitante e visitado, por meio do jantar comunitário (organizado pela comunidade local) e o forró. Os signos durante a festa são espontâneos, é o momento no qual se intensifica o convívio social da comunidade, que encontra no "festar" uma forma de (re) afirmar os laços sociais (Figura 4).

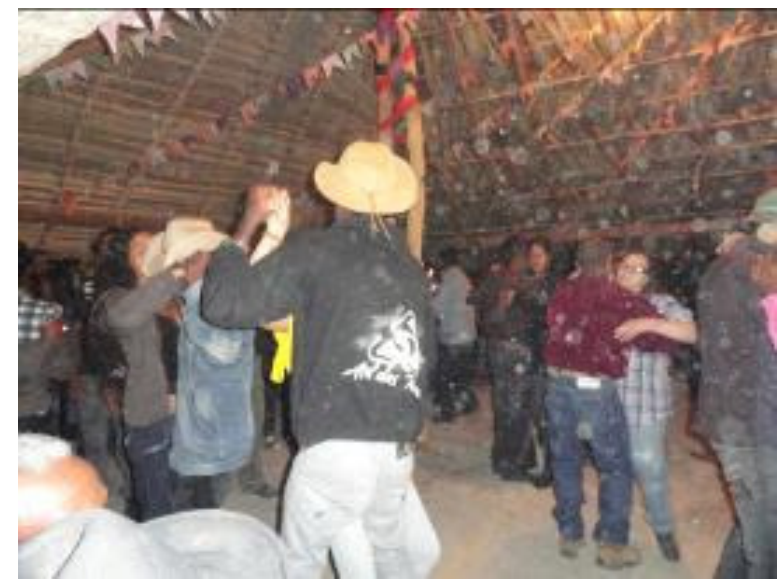

Figura 4: Kalunga e turistas no Forró na Festa de Santo Antônio em Julho de 2011.

Foto: Jorgeanny de Fátima R. Moreira, Julho de 2011.

Figure 4: Forro Kaluga and tourists dancing on the Feast of St. Anthony in July 2011. Photo: Jorgeanny Fatima R. Moreira, July 2011. 
Apesar da perda de algumas de suas práticas simbólicas, como a fabricação de utensílios artesanais e utilização de instrumentos rústicos na agricultura, os Kalunga do Engenho II expressam sua cultura nas manifestações religiosas. "A sociabilidade local é, portanto, construída por meio de agrupamentos de famílias, vinculadas pelo sentimento de localidade, pela convivência, pelas práticas de auxilio mútuo e pelas atividades festivas" (ALMEIDA, 2010, p.14).

As festas que acontecem na comunidade são realizadas com a contribuição de moradores do Engenho II, não há financiamento ou auxílio da prefeitura ou do comércio local. As refeições servidas nas festas são produzidas a partir do envolvimento da população local, tanto com a doação como no preparo dos alimentos.

\section{Desafios e entraves para a efetivação da atividade turística no Engenho II}

No turismo rural as atividades agrícolas não são descartadas, mas continuam a ser desempenhadas pela comunidade. As ocupações ligadas a esse tipo de turismo

[...] de forma alguma, eliminam as atividades agrícolas no espaço em questão, mas contribuem [...], para a complementação da renda familiar, ao possibilitar às famílias de agricultores sua inserção em atividades não-agrícolas (MARAFON; RIBEIRO, 2006, p.120).

Não obstante, no Engenho II a nova atividade econômica é implantada gradativamente, convivendo com as práticas agrícolas, que continuam como fonte principal de renda. A terra é coletiva, os meios de produção pertencem aos moradores da comunidade que contam com a ajuda mútua, de parentes e vizinhos, na época das coIheitas. No entanto, há moradores que trabalham em fazendas vizinhas para a complementação da renda familiar.

A organização do trabalho dos Kalunga na atividade turística, por meio do associativismo, ainda é incipiente, alguns moradores aprovam, enquanto outros acreditam que o turismo não é capaz de melhorar a qualidade de vida da população local. Além disso, existem aqueles que sentem-se intimidados com a presença do visitante, as vezes por timidez ou por não sentir-se confortável com a mudança da rotina, devido ao barulho de carros, vozes e uso intenso dos atrativos.

Uma das moradoras afirma ser impossível ir às cachoeiras com os filhos e esposo nos finais de semana. Nesses dias o fluxo de turistas é intenso, e em alguns casos estão acompanhados por guias vindos do centro urbano de Cavalcante. A moradora conta que sente-se constrangida com tantas pessoas desconhecidas no lugar em que mora. Questionada se tem interesse em aderir aos serviços ligados ao turismo, ela explica que não tem condições financeiras para investir em um empreendimento.

Além do desinteresse e desconfiança de algumas famílias em relação ao turismo, faz-se necessário refletir sobre a degradação ambiental e o impacto cultural 
nessas populações. Em dias de festas, por exemplo, há um aumento considerável de lixo (latas de cerveja, plástico, papel e garrafas de vidro) no Engenho II. Não há coleta desse material, que é queimado por iniciativa dos próprios encarregados das festas. Muitos moradores reclamam dessa atitude, mas concordam que não existe outra opção, já que não há um serviço da prefeitura para remover o material descartado (Figura 5).

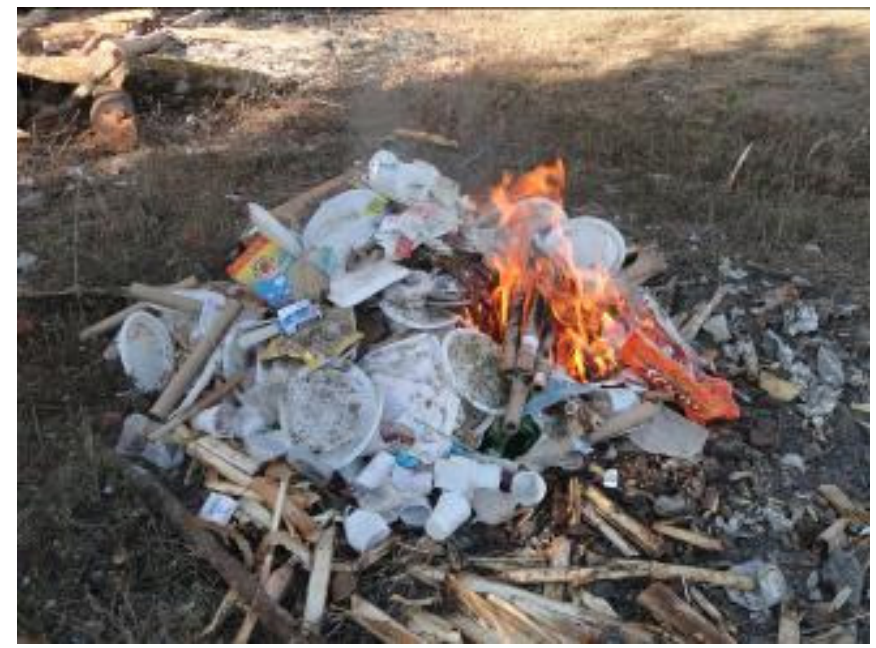

Figura 5: Lixo produzido em uma das festas no Engenho II. Foto: Jorgeanny de Fátima R. Moreira, Julho de 2011.

Figure 5: Waste produced in one of the festivals in the Engenho II. Photo: Jorgeanny Fatima R. Moreira, July 2011.

Essas atitudes não acontecem apenas nos dias de festas, alguns guias locais informaram que muitos turistas deixam plásticos e latas de bebidas no entorno das cachoeiras e das trilhas. Os moradores não conseguem controlar o que os turistas descartam próximos aos atrativos.

A população local tem alternativas para amenizar esses impactos, ao comercializar os produtos mais próximos aos lugares de maior visitação. No entanto, sem orientação, os moradores não se atentam para a oportunidade de eliminar a entrada de produtos adquiridos pelos turistas no centro urbano, e complementar a renda familiar.

Marafon e Ribeiro fazem uma alerta sobre o que falta para o desenvolvimento do turismo no meio rural. Para os autores é fundamental "o envolvimento de órgãos como a Assistência Técnica e Extensão Rural (EMATER), bem como o governo estadual e municipal para a orientação do desenvolvimento de artesanato e doces caseiros, por exemplo" (2006, p. 119).

São poucos os moradores que se dedicam na fabricação de artesanatos ou alimentos para comercialização no Engenho II. A falta de recursos financeiros impede que alguns Kalunga iniciem a fabricação de objetos e alimentos. Os pesquisadores Denardin e Sulzbach (2010), explicam sobre a importância de incentivos para a produção e comercialização de produtos típicos de uma comunidade, ao destacarem o crescimento da procura por produtos de identidade territorial. 
Para esses autores, os produtos produzidos no campo, a partir da agricultura familiar, permitem a esses trabalhadores "uma renda diferencial: uma renda de qualidade territorial" (DENARDIN; SULZBACH, 2010, p. 220). Eles citam exemplos de produtos com identidade territorial, que podem ser materiais ou imateriais, "um queijo produzido artesanalmente em determinado território é um bem" (Idem), da mesma forma que também pode ser considerado um produto com qualidade territorial um grupo folclórico, uma igreja ou gruta, que são símbolos que identificam o território.

F.R. (artesão, agricultor, Kalunga), proprietário de um pequeno alambique, explica seu desejo em aumentar a produtividade, mas não tem capital suficiente para investir em folders ou cartazes para divulgar a cachaça produzida por ele e seus dois filhos. A falta de incentivos e recursos para investimentos também tem provocado a perda de outras práticas, como a fabricação de panelas de barro e de peneiras de folhas dos buritizais.

A produção e comercialização desses materiais podem tornar-se atrativos, uma vez que os artesanatos e alimentos produzidos no campo despertam a atenção dos visitantes. Há relatos na comunidade, sobre algumas famílias que melhoraram a renda familiar com a exploração da atividade turística. Todavia, existem outras que não obtiveram sucesso, devido à dificuldade em se conseguir financiamentos para iniciar o próprio negócio ou pela competitividade entre os empreendedores locais. De acordo com F. R. (condutor de turismo, Kalunga) afirma que os líderes locais ou aqueles que estão envolvidos com a política local se inserem melhor na exploração do turismo.

Existem aspectos negativos na implementação da atividade turística no Engenho II, pois alguns indivíduos dessa comunidade continuam a margem desse processo. A inserção destes na associação, por meio da mobilização e conscientização dos lideres locais, é uma alternativa para apaziguar essas diferenças sociais dentro do próprio grupo.

Além disso, a falta de integração entre a associação e os órgãos públicos ou outras instituições ligadas à cultura e ao turismo de Cavalcante, dificulta o incentivo para a participação mais efetiva de todos os moradores. Segundo o Secretário de Turismo de Cavalcante, já aconteceram minicursos de capacitação para os funcionários municipais envolvidos em projetos da área de turismo, mas a programação dos cursos não possuía foco em serviços de condução.

\section{Considerações finais}

As atividades desenvolvidas na comunidade Kalunga do Engenho II têm se mostrado como estratégia capaz de romper com a dependência desse povo aos sistemas hegemônicos do mercado turístico. Seis dos Kalunga entrevistados veem no desenvolvimento turístico da região, um meio de permanecer no território. Alguns jovens, condutores de turistas, voltaram de cidades como Brasília e Goiânia ${ }^{1}$, pois não conseguiram identificarse ou adaptar-se a rotina dessas metrópoles. A relação de pertencimento com o lugar é forte e preponderante para que muitos resistam ao desemprego e a precariedade de infraestrutura no Engenho II.

No entanto, há grupos que possuem interesses diferentes daqueles que vivem do turismo. Há intenções diversas, como o desejo de continuar o trabalho em suas roças e comercializar o excedente nas cidades; de emigrar para o centro urbano de Cavalcante; de viver em grandes metrópoles, na expectativa de melhores condições de vida; e há o 
grupo dos idosos, que acredita no turismo como meio de atrair forasteiros responsáveis pelo barulho e conflitos na comunidade.

Apesar desses grupos contrários, a exploração turismo rural, étnico e cultural no território Kalunga, pode ser uma oportunidade para o desenvolvimento local, a partir da apropriação de recursos específicos, tanto materiais como imateriais presentes na comunidade do Engenho II.

É evidente que não há o envolvimento de toda a população, e isso provoca conflitos de interesses e ruptura entre os laços historicamente estabelecidos com o lugar, ressaltando a desvalorização da cultura local. O comportamento desinteressado de alguns moradores acrescenta-se ao lugar turístico pautado na efemeridade das relações, entre visitantes e visitados. Na medida em que o turismo rural se consolida com base na economia solidária, a população deve intervir no tipo de turista que deseja na comunidade, estreitando as relações com estes e com o grupo local.

O distanciamento de alguns grupos - contrários ao desenvolvimento do turismo dificulta a criação de mecanismos institucionais, capazes de regular o emprego dos recursos e dos benefícios locais, para o desenvolvimento dessa atividade.

No entanto, é fundamental a participação de todo o grupo social para que se efetive uma organização comunitária, no sentido de difundir e sensibilizar toda a população local acerca das possibilidades para o desenvolvimento social, a partir da exploração dos potenciais naturais e culturais da região.

\section{Referências bibliográficas}

ALMEIDA, M.G. Território de Quilombolas: pelos vãos e serras dos Kalunga de Goiás patrimônio e biodiversidade de sujeitos do Cerrado. Revista Ateliê Geográfico - Edição Especial. V. 1, n. 9, fev 2010, p. 36-63.

ALMEIDA, M.G. Turismo e os Paradoxos no Consumo e Conservação do Ambiente. Revista Ateliê Geográfico. Goiânia: v. 1, n² 2, dez./2007, p. 102-118.

ARRAIS, T.A. Geografia Contemporânea de Goiás. Goiânia: Ed. Vieira, 2004.

BLANCO, E.S. O Turismo Rural em Áreas de Agricultura Familiar: as "novas ruralidades" e a sustentabilidade do desenvolvimento local. In: BARTHOLO, R.; SANSOLO, D.G.; BURSZTYN, I. (Orgs.). Turismo de Base Comunitária: diversidade de olhares e experiências brasileiras. Rio de Janeiro: Letra e Imagem, 2009.

BRASIL. Turismo rural: orientações básicas. Secretaria Nacional de Políticas de Turismo, Departamento de Estruturação, Articulação e Ordenamento Turístico, Coordenação Geral de Segmentação - Brasília: Ministério do Turismo, 2008. 53 p.

BRASIL. Estruturação do produto turístico. Secretaria de Políticas do Turismo. Ministério do Turismo - Florianópolis: SEADIUFSC, 2009.

CAMPANHOLA, C.; SILVA, J.G. O agroturismo como fonte de renda para o pequeno agricultor brasileiro. In: ALMEIDA, J.A.; RIEDL, M. (orgs). Turismo Rural: ecologia, lazer e desenvolvimento. Bauru: EDUSC, 2000.

DENARDIN, V.F.; SULZABACH, M.T. Produtos com Identidade Territorial : o caso da farinha de mandioca no Litoral Paranaense. In: SAQUET, M.A.; SANTOS, R.A. (Orgs). Geografia Agrária, território e desenvolvimento. São Paulo: Expressão Popular, 2010. 
INVING, M.A. Reiventando a reflexão sobre turismo de base comunitária: inovar é possível? In: BARTHOLO, R.; SANSOLO, D.G.; BURSZTYN, I. Turismo de Base Comunitária: diversidade de olhares e experiências brasileiras. Rio de Janeiro: Letra e Imagem, 2009.

MARAFON, G.J.; RIBEIRO, M.A. Agricultura Familiar, Pluriatividade e Turismo Rural: reflexões a partir do território fluminense. Revista Rio de Janeiro. N. 18-19, jan.-dez. 2006.

MINISTÉRIO DA CULTURA. Fundação Cultural Palmares. Disponível em http:// www.palmares.gov.br. Acesso em 14 de Outubro de 2010.

MOLETTA, V.F. Turismo Rural. Série Desenvolvendo o Turismo. Vol. 6. Porto Alegre: SABRAE/RS, 2002.

SANSOLO, D.G.; BURSZTYN, I. Turismo de Base comunitária: potencialidades no espaço rural brasileiro. In: BARTHOLO, R.; SANSOLO, D.G.; BURSZTYN, I. Turismo de Base Comunitária: diversidade de olhares e experiências brasileiras. Rio de Janeiro: Letra e Imagem, 2009.

SWARBROOKE, J. Turismo Sustentável: Meio Ambiente e Economia, vol. 2. São Paulo: Editora Aleph, 2000.

\section{Nota:}

${ }^{1}$ Consumidores que compraram serviços de turismo em pacotes ou em partes nos dois anos anteriores à realização da pesquisa.

Jorgeanny de Fátima Rodrigues Moreira: Universidade Federal de Goiás, Goiânia, GO, Brasil.

Email: jorgeannyf@hotmail.com

Link para o currículo Lattes: http://lattes.cnpq.br/8503948463067223

Maria Geralda de Almeida: Universidade Federal de Goiás, Goiânia, GO, Brasil.

Email:mgdealmeida@gmail.com

Link para o currículo Lattes: http://lattes.cnpq.br/4465452999284335

Data de submissão: 31 de maio de 2012

Data de recebimento de correções: 16 de junho de 2013

Data do aceite: 18 de junho de 2013

Avaliado anonimamente 